\title{
The Inverted Sublimity of the Dark Psytrance Dance Floor
}

\author{
BOTOND VITOS \\ ELTE UNIVERSITY, BUDAPEST (HUNGARY)
}

from

the

floor

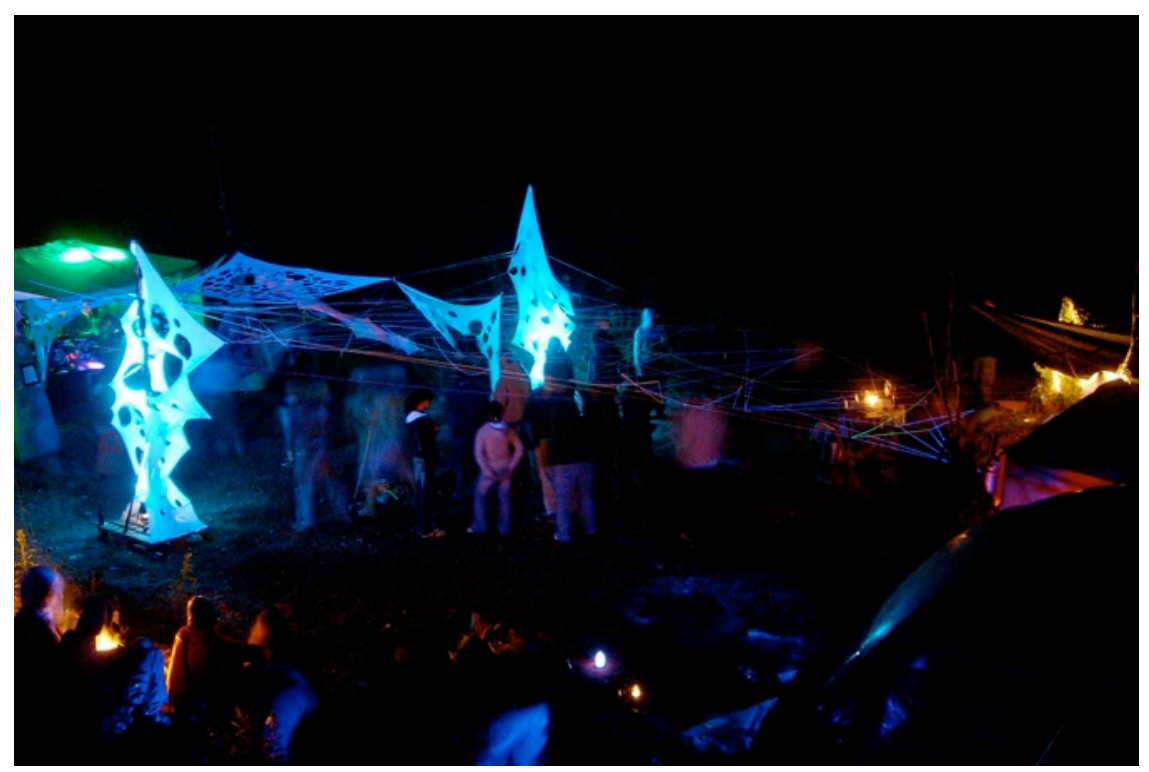

Twisted Trip party 1, Germany, 2007. Photo by Richard Cattien

Based on my experiences and understanding of Hungarian, Czech and Greek psytrance parties, this text offers a concise view on the aesthetic categories triggered by dark psychedelic dance floors. Such dance floors incorporate crowds of varying sizes, influenced by psychedelic drugs, and dancing through the night (and sometimes through the morning) on a music which can be considered the hard core of psytrance. Quality darkpsy music involves the organic evolution and breakdown of distorted and interwoven sound layers of high complexity, with an underlying tempo which exceeds $150 \mathrm{BPM}$, and often collapses down to zero or speeds up to hyperspeed. The main preoccupation of this genre seems to be the continuous transgression of its own perverted boundaries, both musically and semantically: the distortion, reversal, speeding up and destruction of rhythms and layers, the use of both menacing and nonsensical sound patterns, the continuous oscillation between horror and humor creates its characteristically demented atmosphere. When consuming psychedelic drugs such as the popular LSD, the flow of the music captivates the participant, and triggers a series of hallucinations, which traverse beyond and obscure the categories of everyday reality, disengaging the participant into a zone of the unknown. In this manner the dance floor generates an excess of (un)reality, a Baudrillardian (1988) simulated medium from which distinct aesthetical sensibilities arise. 
Sample tracks by Russian darkpsy artist Psykovsky:

http://www.youtube.com/watch?v=WLsOZ6Ijndg

Psykovsky "Isshoni Taides"

http://www.youtube.com/watch?v=nCBWzNQ-1UM

Psykovsky "P.S.Y. Love You"

To identify this aesthetics I will borrow my key concept from Lyotard (1991), who offers a perspective on the aesthetic category of the sublime. In his discussion he evokes the Kantian sublime situation, in which an absolutely large object, which can only be thought as an Idea of reason, collapses the faculty of representation. The human imagination fails to provide a representation corresponding to this Idea, and this employs an indeterminate aesthetic pleasure that mixes pleasure with pain. The failure of expression gives rise to pain, which in turn engenders a double pleasure through two acts: firstly, the imagination aims to harmonize its object with the Idea of reason, and secondly, the inadequacy of presentations acts as a negative sign of the immense power of ideas. The absoluteness of the Idea is ultimately revealed by negative presentation. The sublime sentiment is called forth in romantic and avant-garde art, which are both preoccupied with the presentation of the unpresentable. However, while the romantic nostalgia tries to find the unpresentable at a great distance, as a lost origin or end, the avant-gardes concentrate on what is the closest, on the very matter of artistic work. Lyotard also recalls Burke's thoughts on the negative pleasure of delight. Certain objects and sensations are pregnant with the threat of our self-preservation; the sublime confronts us with the terror of an immense spiritual passion which carries the threat of nothing further happening (that is, the extinguishment of the system). The sublime sentiment derives from the relief that despite and within this threatening void, something still happens and occupies a place, a place which is merely "here".

While the dark psytrance dance floor is preoccupied with a similar problematic (the confrontation with the threat of the dissolution of the system), it situates the recipient in a different position, to a place which is not "here", but "there". If the sublime situation concerns the confrontation with the infinite ocean which surrounds and threatens our island of existence, then the dance floor will throw the subject in these waves. Through this process, not the ability of representation, but that of conceptualization, is abolished; while acts of conceptualization would draw around the subject subsequent islands of interpretation, these islands are repeatedly dissolved by demented (music) waves. The dance floor freezes and expands the very moment of entering the zone of the forbidden/inaccessible (in the following moment, or immediately after crossing the frontier, the prohibition dissolves, and the unknown becomes part of the system). The impossible attempt of the dance floor aims at experiencing the immensity of Otherness out "there", without transferring it "here" (without integrating it into the Self, thus dissolving or understanding it). Therefore its very goal is being as ambiguous and "spaced out" as possible. Psytrance parties are generally oversaturated with unusual, fantastic or bizarre decor and visual art, sometimes the partygoers themselves appear in costumes, and the use of symbols, such as sci-fi motifs or aliens, further dislocates the psychedelic experience of the participants. 


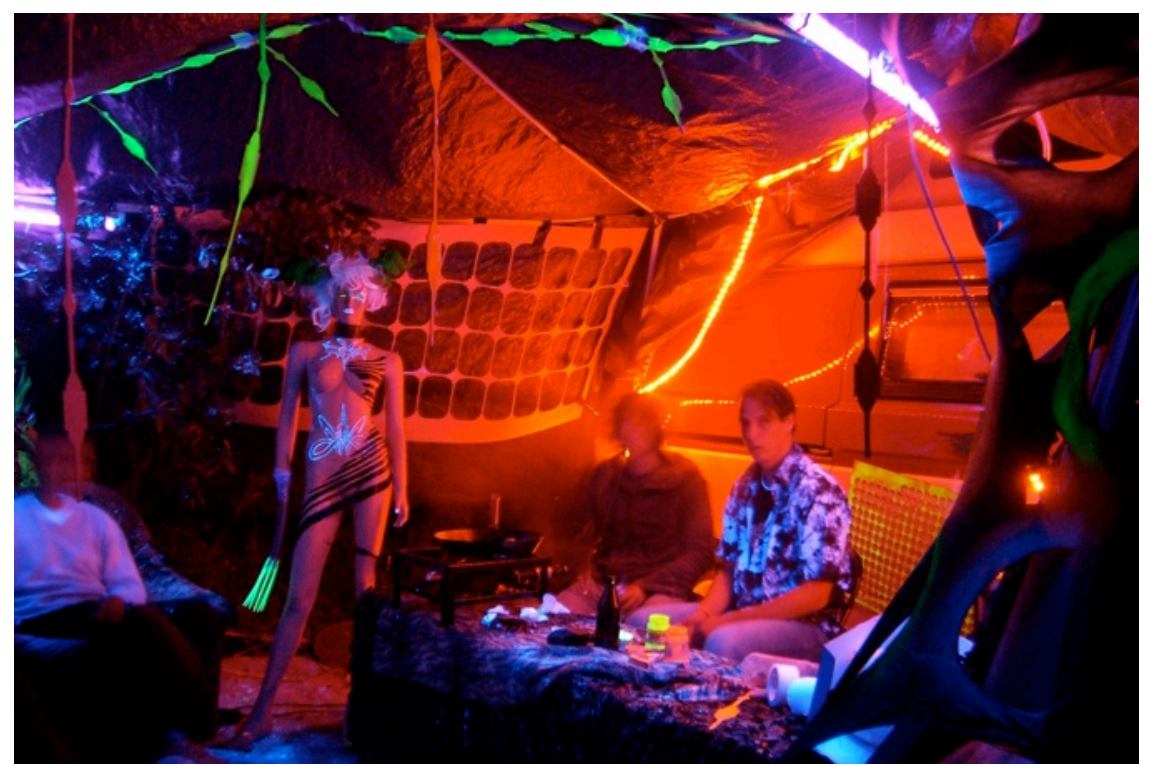

Twisted Trip party 2, Germany, 2007. Photo by Richard Cattien

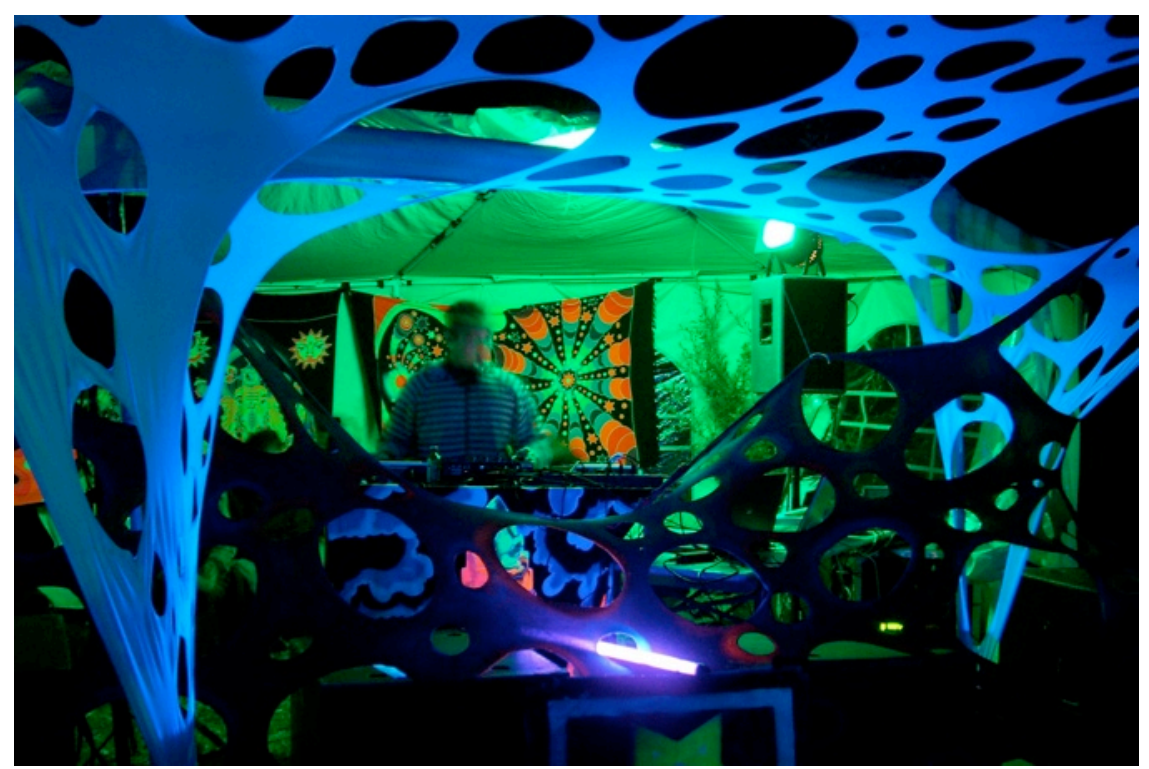

Twisted Trip party 3, Germany, 2007. Photo by Richard Cattien

Both the sublime and the darkpsy experience approach the frontier between world and un-world (between the system and its dissolution, the articulated and the unarticulated, finite and infinite); however, their perspectives are inverted. The sublime conceives its un-presentable entity from within the system, and conceptualizes it in the form of an Idea of Reason. This very Idea occupies a place in the structure of the sys- 
tem. The dance floor inverts the sublime situation by attempting to explore the frontier from the outside, from an impossible space where all meaning is rendered inconceivable (including the meaning of the experience). This semantic breakdown is triggered by the positive presentation of a simulated, multidimensional freakshow. The show can be regarded as the inversion of the avant-garde sublime, because its obscure object of desire resides not in the great distances of the romantic thought, but in the very proximity, in the raw material of the dance floor: this hell broth is composed by the conglomeration of the weird musical and visual environment (an interplay of technology and nature), the interactive audience, and the drug.

According to one of my informants, on the ideal dance floors the participants, under the influence of psychedelic drugs, are unable to do anything else, than "dancing' with twisted, out-of-this-world movements on the completely spaced out music". The working mechanisms of psychedelics (most commonly LSD, and also other chemicals, the effects of which may vary) assure that each recipient acquires a different (alien) perspective on the performance, the only unifying point being the common unknowing of what exactly is going on. The demented dance floor simulates a modified tower of Babel, urging for the dissolution of the platonic Ideal, which is not collapsed by the multitude of its incomprehensible languages, but exploits this entropy, and keeps on growing or developing as an organic structure. In contrast with the formless Kantian sublime, the inverted sublimity of the dance floor experience arises from the constant rioting, whirling, and - in a grotesque manner - from the reflexive transgression of forms.

The party ultimately generates a system which artificially simulates or expresses the lack of rules: this is embedded in the very structure of the dance floor. The entropy of this structure is guaranteed by both the unpredictable nature of the psychedelic trip and the vague environment of the party. The latter is not meant to stabilize the experience in any way, but maximizes the detachment from "this world". The ideal psychedelic environment transfers the participant to an unknown place, such as an alien planet, through the simulation of the dissolution or the evasion of the system. The aesthetic category disengaged in this process is that of an inverted sublime. An opposition with the sublime was already characteristic to the aesthetics of the grotesque (Bakhtin 1968), an aesthetics which has slipped into psytrance as well. Unlike the sublime sentiment which arises from the failure of expressing a conceivable entity of infinite proportions, the darkpsy dance floor attempts to express something which is inconceivable or unarticulated in the system. While the sublime relief is triggered by the fact that something happens despite of everything, on the dance floor nothing meaningful happens, or even: everything that is not meaningful happens.

http://www.youtube.com/watch?v=Q1oDPZ5zc3w

Argentinian duo Megalopsy performing at Psycrowdelica festival, Germany, 2009

\section{References}

Bakhtin, Mikhail. 1968. Rabelais and His World. Bloomington: Indiana University Press.

Baudrillard, Jean. 1988. "Simulacra and Simulation”. In Mark Poster (ed), Selected Writings, pp. 166-184. Stanford University Press,

Lyotard, Jean-Francois. 1991. The Inhuman. Reflections on Time. Stanford University Press. 


\section{Discography}

Psykovsky. 2009. Da Budet. Tantrumm Records (CD): tancd007.

http://www.discogs.com/Psykovsky-Da-Budet/release/1621040

\section{Author Biography}

Botond Vitos is a cultural anthropology graduate from the ELTE University, Budapest, Hungary where he recently completed his MA on the Czech psytrance scene. His research interests include EDMC studies, the cultural contexts and meanings of drug use and the relationships between music and technology. 